\title{
PODER INDUTOR DO IDEB SOBRE AS POLÍTICAS EDUCACIONAIS DO MUNICÍPIO DE CURITIBA
}

Douglas Danilo Dittrich*

Resumo: O trabalho aqui sistematizado é parte dos resultados apresentados na dissertação do autor defendida em agosto de 2010. Neste trabalho encontram-se sistematizados três flagrantes da política educacional do município de Curitiba com potencial de gerar melhoria no IDEB dos anos iniciais do Ensino Fundamental, expressando o poder indutor do IDEB na geração de políticas educacionais. Os flagrantes revelam um processo de redefinição curricular sustentado nos descritores da Prova Brasil e da Provinha Brasil, e políticas de qualificação dos professores e professoras em serviço, as quais passaram a ser balizadas pelo objetivo de melhorar o IDEB do município para as séries iniciais do Ensino Fundamental.

Palavras-chave: Política Educacional. IDEB. Prova Brasil. Avaliação. 


\section{Introdução}

O problema da pesquisa aqui sistematizada centrou-se em tentar perceber a existência de movimentos específicos da política educacional do município de Curitiba que confirmassem o poder indutor do Índice de Desenvolvimento da Educação Básica (IDEB).

Para responder minimamente a essa questão, foi necessário cotejar diversas fontes de informação, para que fosse possível flagrar, dentro da característica fluida da política, elementos concretos de alteração da política educacional do município de Curitiba com potencial de gerar impacto na melhoria do IDEB do município.

Esclareço que o trabalho aqui apresentado constitui-se de parte de um trabalho maior, minha dissertação, defendida em agosto de 2010, na Universidade Federal do Paraná, no Programa de Pós-Graduação em Educação na Linha de pesquisa de Política Educacional, e que, em sua totalidade representa apenas um pequeno passo para a compreensão do impacto das políticas educacionais sobre o IDEB, e do IDEB sobre as políticas educacionais.

Partindo da premissa de que "não é indiferente fazer as coisas ou deixar de fazê-las, ou fazê-las de uma determinada maneira ou de outra" (Santos Guerra, 2007, p. 105), é que para esta pesquisa determinadas políticas potencializavam uma melhoria no IDEB, ou vinculam-se à melhoria do IDEB do município, sendo, portanto, geradas e implementadas por força do poder indutor próprio do IDEB.

O grau de minúcia apresentado pelas leis ou prescrições aqui flagrados, somente agrava mais o problema, pois, segundo Santos Guerra (2007, p. 99):

Essa minuciosidade possui duas causas, de origem paradoxal: por um lado, os próprios professores pedem instruções precisas sobre o que têm de fazer. Isso que tem de ser feito, como deve ser feito? Por outro lado, 
os governantes, preocupados com a capacidade de interpretações e de concreção do professorado, inquietos com a hermenêutica possivelmente desafortunada, tratam de deixar muito claro o que se deve fazer.

Para esta pesquisa, foram adensados dados referentes às orientações da Secretaria Municipal de Educação para os momentos de formação continuada dos professores da rede municipal, denominada Semana de Estudos Pedagógicos (SEP), cujos critérios para aprovação foram explicitados aqui pelo Ofício Circular n. 013/2009.

Também no aspecto das políticas de formação continuada dos professores e professoras - o "Projeto Escola \& Universidade" -, foi importante para a confirmação do processo de adaptação das políticas educacionais do município de Curitiba ao IDEB.

O processo de indução ocorrido no município de Curitiba e apresentado neste estudo merece destaque, porém, requer maior aprofundamento, dada sua complexidade e amplitude, pois revela uma nova característica da política educacional para o município, a qual abriu mão da sua condição de criadora de "boas soluções" para assumir o papel de reprodução do que vem do governo federal, o que é raro na política municipal, em todos os âmbitos de interferência da política.

\section{Flagrantes do Poder Indutor do IDEB}

As pesquisas desenvolvidas pela área denominada de "movimento teórico prático sobre eficácia escolar" (Murillo Torrecilla, 2005b, p. 466) já apresentam uma produção significativa, sobretudo no que potencializa ou não a uma escola ser eficaz ${ }^{1}$ em seu papel de ensinar bem a todos os alunos.

Um dos elementos levantados por Murillo Torrecilla, e central da política educacional, diz respeito à "qualidade curricular" (Murillo Torrecilla, 2005a, p. 223).

$\mathrm{O}$ autor destaca a importância dos elementos que compõem e conformam a qualidade do currículo, apontando quatro 
elementos significativos para essa condição: o primeiro diz respeito aos objetivos claros, o segundo as estruturas das aulas e lições, o terceiro trata da necessidade permanente de reforço e retroalimentação do trabalho pedagógico, e, por fim, atenção à diversidade.

Sammons (2008, p. 363), ao debruçar-se sobre as "características-chave das escolas eficazes", também salienta o elemento "ensino e objetivos claros".

Dentro das ações desenvolvidas pela Secretaria Municipal de Educação com vistas à melhoria do IDEB do município, é possível perceber a incorporação do primeiro elemento apresentado por Murillo Torrecilla, e o de Sammons.

No município de Curitiba este processo consolidou-se pela reorganização curricular onde as Diretrizes Curriculares para a Educação Municipal de Curitiba perderam seu poder de dar diretriz à educação de Curitiba, passando tal poder para as Matrizes de Referência da Prova e da Provinha Brasil.

O movimento da política educacional mencionado anteriormente foi percebido por três instrumentos distintos de informação, sendo o primeiro a entrevista da representante da Secretaria Municipal de Educação de Curitiba concedida a Zampiri (2009). Nesse documento, que se encontra presente no Anexo III da dissertação da autora anterior, ela afirma:

Então em 2005, a primeira ação que a gente decidiu com todos os riscos que ela poderia ter e sofrer, a gente propôs que as escolas revissem o que estavam ensinando em cada uma das áreas de conhecimento e a questão curricular, ela é organizada aqui dentro. As diretrizes curriculares são postas por esse departamento em função evidente das diretrizes curriculares nacionais, estaduais e em função da legislação, mas o município de Curitiba tem que ter sua visão desde a educação para o município e dessa revisão das propostas curriculares... A gente mobilizou as escolas para rever o que que [sic] estavam ensinando num primeiro momento (Zampiri, 2009, p. 173-174). 
Mais à frente na entrevista há uma passagem que precisa ser analisada em conjunto com a anterior, na qual a entrevistada afirma que "o professor tem que saber ensinar... Nosso problema é que os professores não sabem como ensinar o conteúdo, obviamente, eu acho que nosso problema é esse, tanto nos anos iniciais como nos anos finais" (Zampiri, 2009, p. 176). Portanto, a ação descrita anteriormente tinha como objetivo "rever" com os professores e professoras o que e como deveria ser ensinado por eles, o que poderia ter contribuído para potencializar um ensino claro e objetivo.

Ao serem cotejadas as considerações de Murillo Torrecilla e Sammons com a percepção da entrevistada frente à falta de foco das escolas, torna-se possível afirmar que as discussões referentes às diretrizes curriculares constituíram-se num processo que visou dar direção mais objetiva e clara ao fazer pedagógico das escolas, sobretudo se for considerado que "no início as escolas mostravam, elas tinham 20 projetos às vezes, e a gente perguntava: 'qual é o seu projeto pedagógico?' porque era uma dispersão, uma falta de foco na questão do ensino" (Zampiri, 2009, p. 177). Isso pode ser resumido como um processo de percepção de um dos problemas das escolas no desempenho frente às avaliações em larga escala, qual seja, a relação intrínseca entre o que deve ser ensinado e o que será cobrado em forma de avaliação estandardizada, ou seja, o poder de indução de quem controla as avaliações para definir o que deve ser ensinado.

Santos Guerra (2007) ao abordar "a cultura que gera a avaliação nas escolas", traz a tona a "cultura da subordinação" afirmando que:

O conhecimento do qual o avaliador é o depositário se torna o conhecimento hegemônico, o conhecimento realmente importante, porque é com referência a ele que se fará a avaliação. Quem toma nota do que dizem os colegas? Este conhecimento não tem valor, pois não fará parte da avaliação. O conhecimento importante é aquele de que tratará a avaliação. 
Aquele que avalia tem poder. Impõe normas, adota critérios e fornece explicações. Pode conseguir que o outro faça o que ele deseja, pois sua influência converte-se em poder. (Santos Guerra, 2007, p. 45-46).

$\mathrm{Na}$ reconstrução curricular, ocuparam lugar de destaque os "Cadernos Pedagógicos", os quais foram apresentados pela secretaria municipal de educação como "um instrumento paradidático, que vem compor o conjunto de recursos de que dispõem as equipes de nossas escolas para o planejamento de processos de ensino" (Curitiba, 2008a, p. 3).

Por apresentar, em seu interior, possíveis formas de trabalhar com os conteúdos, essa ação de definição de "objetivos claros" agregou o segundo aspecto curricular, configurando uma ação de interferência na "estrutura das aulas e lições".

Assim, é possível perceber a intervenção da política educacional do município em dois aspectos específicos da política curricular:

Primeiro: definição das Matrizes de Referência para a Prova e Provinha Brasil como currículo de fato. Segundo: organização dessas matrizes em Cadernos Pedagógicos, com exemplos de como trabalhá-las pedagogicamente, agindo para tornar os conteúdos e os objetivos mais claros.

Essas ações caracterizam, em parte, a preponderância das Matrizes de Referência da Prova e da Provinha Brasil sobre as Diretrizes do município, porém, ainda há três outros momentos em que esse movimento pode ser flagrado, que passam a ser relatados a seguir.

\section{Primeiro movimento:}

Pode-se perceber que as diretrizes para a área de Língua Portuguesa/alfabetização trabalham com quatro eixos: a "leitura - condição básica para a consolidação da cidadania", a "prática da oralidade", a "prática da escrita" e a "análise linguística" (Curitiba, 2006, p. 208-219). Já os Cadernos Pedagógicos centram-se em apenas três eixos: 
[...] os encaminhamentos sugeridos neste caderno são possibilidades de trabalho que devem privilegiar atividades de leitura, de entendimento dos funcionamentos do sistema alfabético de escrita, de produção de texto e de análise linguística. (Curitiba, 2008a, p. 10, grifo meu)

O trabalho dos Cadernos Pedagógicos centra-se naquilo que se quer e pode medir, e não o que é necessário, desejável e indispensável de ser ensinado, pelo fato de apresentar dificuldade para ser medido, como é o caso da oralidade.

Para a Língua Portuguesa, a Matriz de Referência da Prova Brasil apresenta 6 tópicos, para os quais são listados 15 descritores, que objetivam perceber a competência dos alunos em cada tópico.

Para essa etapa da educação, $3^{\mathrm{a}}$ e $4^{\mathrm{a}}$ séries, os Cadernos Pedagógicos fizeram o mesmo movimento expresso anteriormente, ou seja, adaptaram-se às definições do governo federal, tentando enquadrar professores e professoras para que seus trabalhos fossem balizados pelas Matrizes Curriculares da Prova Brasil e não pelas Diretrizes Curriculares do município.

Destaque-se que, enquanto os Cadernos Pedagógicos apresentam 7 temas a serem trabalhados, as Diretrizes Curriculares do município são 32.

No Caderno Pedagógico dirigido às $3^{\mathrm{a}}$ e $4^{\mathrm{a}}$ séries, na área de Matemática, os conteúdos estão organizados em 7 temas a serem trabalhados, e as Diretrizes municipais contêm 37 conteúdos, e as Matrizes de Referência da Prova Brasil estão organizadas em 4 temas, com 28 descritores.

O Quadro 1 permite uma comparação objetiva dos dois documentos. 
Quadro 01- Correlação entre as matrizes de referência da Prova Brasil e os Cadernos Pedagógicos da Prefeitura Municipal de Curitiba, para a área da Matemática.

\begin{tabular}{|c|c|c|}
\hline & $\begin{array}{c}\text { Matrizes de Referência da Prova } \\
\text { Brasil }\end{array}$ & Cadernos Pedagógicos \\
\hline \multirow{7}{*}{$\begin{array}{l}\text { O que deve } \\
\text { ser trabalhado }\end{array}$} & \multirow{3}{*}{ Espaço e Forma } & $\begin{array}{c}\text { Formas Tridimensionais - Sólidos } \\
\text { Geométricos }\end{array}$ \\
\hline & & Formas Tridimensionais e Bidimensionais \\
\hline & & Formas Bidimensionais \\
\hline & Grandezas e Medidas & Medidas de Comprimento e Perímetro \\
\hline & $\begin{array}{l}\text { Números e Operações/Álgebra e } \\
\text { Funções }\end{array}$ & Números Racionais \\
\hline & \multirow{2}{*}{ Tratamento da Informação } & Estatística \\
\hline & & Probabilidade \\
\hline
\end{tabular}

Fonte: Brasil (2008) e Curitiba (2008c).

Considerando o conteúdo exposto no confronto dos dois instrumentos de apoio pedagógico contidos no Quadro 1, que são as Matrizes de Referência da Prova Brasil e os Cadernos Pedagógicos, percebe-se o movimento da política educacional do município para se aproximar do conteúdo cobrado pelo MEC em suas avaliações, ao transformar as referidas matrizes no conhecimento a ser trabalhado pelos professores, agregando a elas encaminhamentos metodológicos e dicas para que os professores possam efetivar a aprendizagem do que ali está listado.

É preciso esclarecer que não se está apresentando um julgamento de valor sobre essa ação. Trata-se de detectar o poder indutor das políticas de avaliação censitárias, e, por conseguinte do IDEB.

\section{Segundo movimento:}

O processo de incorporação das Matrizes de Referência, tanto da Prova Brasil quanto da Provinha Brasil, como o verdadeiro currículo do município pode ser confirmado também no projeto de qualificação continuada, o Projeto Escola \& Universidade, que compõe o "Programa de Qualidade da Educação" (Curitiba, 2009a, p. 5). Esse programa objetiva aprimorar o fazer pedagógico dos professores por meio da contribuição científica 
e técnica das instituições de ensino superior.

O projeto Escola \& Universidade constitui-se também em incentivo financeiro, já que os professores que têm projetos aprovados têm direito a bolsa auxílio de $\mathrm{R} \$ 1.200,00$, que é dividida em 4 parcelas de $\mathrm{R} \$ 300,00$ e atende aproximadamente 5.000 professores por ano.

Com o advento da Prova e da Provinha Brasil, o manual do projeto Escola \& Universidade, passou a nortear-se pelas Matrizes de Referência da Prova Brasil e da Provinha Brasil, sendo este o primeiro passo formal que expressa que o município passou a assumir as Matrizes como o que deve balizar o fazer pedagógico no interior das escolas.

A incorporação das Matrizes de Referência aparece no manual do projeto Escola \& Universidade ${ }^{2}$, primeiramente, no item 9, "Critérios para a elaboração dos projetos" (Curitiba, 2009a, p. 13), que traz, nos subitens 9.3.1 e 9.3.2, as seguintes orientações:

9.3.1. Os temas das Matrizes de Referências para nortear a escrita dos projetos deverão fazer relações necessárias com as áreas do conhecimento do Ensino Fundamental das Diretrizes Curriculares e demais documentos oficiais do Município de Curitiba.

9.3.2. Os temas dos projetos Escola \& Universidade deverão estar articulados ao projeto pedagógico e ao levantamento e análise realizados pelo coletivo das unidades educativas a partir da avaliação quantitativa e qualitativa:

- de acordo com os descritores das Matrizes de Referências da Provinha Brasil (avaliação e medida no processo de alfabetização).

- de acordo com os descritores das Matrizes de Referência da Prova Brasil (Língua Portuguesa e Matemática). 
- do Índice de Desenvolvimento da Educação Básica (IDEB).

- dos resultados da avaliação do rendimento escolar da RME 2007-2009 (Língua Portuguesa e Matemática). (Curitiba, 2009a, p. 14)

Se, de um lado, no manual consta também a necessidade de haver relação com as "Diretrizes Curriculares e demais documentos oficiais do Município de Curitiba”, por outro lado, o que constava como elemento para a avaliação, classificação ou mesmo desclassificação dos projetos inscritos não era a presença de documentos municipais embasando os projetos, mas sim a vinculação do projeto com as matrizes, tanto da Prova como da Provinha Brasil. A presença de tais matrizes nos projetos recebia 3 pontos na avaliação, de um total de 10 , critério este que não era considerado para as diretrizes do município.

Todos os avaliadores dos projetos receberam uma tabela de pontuação, na qual era apresentado o peso para cada critério a ser avaliado. Dentro desses critérios, e com peso 3, o mais significativo, encontram-se as Matrizes de Referência da Prova e da Provinha Brasil, o que pode ser conferido na Figura 01.

Cabe chamar a atenção para duas situações. A primeira se refere ao fato de as Matrizes de Referência apresentarem o maior peso entre os 6 critérios, respondendo sozinhas por quase um terço da pontuação máxima possível. A segunda situação a ser destacada diz respeito ao manual do projeto, que faz menção às Diretrizes Curriculares do município, mas não lhes dá expressão na avaliação dos projetos, o que reforça a conclusão de que as Diretrizes Curriculares do município existem, mas ocupam um papel figurativo, burocrático, já que o que passou a incorporar o status de currículo efetivo, ou o que vem realmente amparando o fazer pedagógico das escolas na rede municipal de Curitiba, é o que o Ministério de Educação diz que estará avaliando.

A Figura 01 apresenta a tabela entregue para os avaliadores 
dos projetos, na qual podem ser observados, na parte específica ao Ensino Fundamental, o peso já mencionado para os projetos que contemplam em seu conteúdo o trabalho com as matrizes de referência das avaliações do governo federal e a ausência de pontuação para projetos referenciados nas Diretrizes Curriculares do município.

Figura 01- Descrição dos critérios e pesos para a avaliação dos projetos Escola \& Universidade.

\begin{tabular}{|c|c|c|c|}
\hline \multicolumn{2}{|c|}{$\begin{array}{l}\text { PREFEITURA MUNICIPAL DE CURITIBA } \\
\text { SECRETARIA MUNICIPAL DA EDUCAÇÃO } \\
\text { SETPARTAMENTO DE TECNOLOGIA E DIFUSÄO EDUCACIONAL } \\
\text { CURITIBA } \\
\text { COORDENAÇÃO DO PROJ ETO ESCOLA \& UNIVERSIDADE }\end{array}$} & & 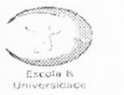 \\
\hline \multicolumn{4}{|c|}{ TABELA DE PONTOS PARA OS CRITÉRIOS DE AVALIAÇÄO DE PROJETOS/ 2009} \\
\hline \multirow[b]{2}{*}{ CRITÉRIO } & \multicolumn{3}{|c|}{ PESO $-10,0$} \\
\hline & SIM & NAO & PARCIALMENTE \\
\hline c) Há coerència entre titulo objetivos, justificativa, metodologia e estratégias? & 3,0 & 0 & - \\
\hline d) A fundamentaçāo teórica está coerente com a proposta do projeto? & 2.5 & 0 & 125 \\
\hline e) Onservou-se plágios cópias literais de textos sem fazer referências? & 0 & 2.5 & 125 \\
\hline f) Está redigido de forma coerente, clara e objetiva? & 1,5 & 0 & 0.75 \\
\hline $\begin{array}{l}\text { g) Está redigido na formataçáo indicada pela ABNT (Associaçào Brasileira de } \\
\text { Normas Tóonicas)? }\end{array}$ & 0.5 & 0 & 0.25 \\
\hline \multicolumn{4}{|l|}{ Ensino Fundamental } \\
\hline \multirow[b]{2}{*}{ CRITÉRIOS } & \multicolumn{3}{|c|}{ PESO -10.0} \\
\hline & $\operatorname{siM}$ & NÄO & PARCIALMENTE \\
\hline $\begin{array}{l}\text { a) Contém descritores das Matrizes de Referências da Provinha Brasil? } \\
\text { b) Contém descritores das Matrizes de Referências da Prova Brasil em Lingua } \\
\text { Portuguesa e/ou Matemática? }\end{array}$ & 3,0 & 0 & The \\
\hline c) Há coeréncia entre titulo objetivos, justificativa, metodologia e estratégias? & 2.0 & 0 & 1.0 \\
\hline d) A fundamentaçâo teórica está coerente com a proposta do projeto? & 1.5 & 0 & 0.75 \\
\hline e) Observou-se plágios cópias literais de textos sem fazer referências? & 0 & 1.5 & 0.75 \\
\hline i) Está recigico de forma coerente, clara e objetiva? & 1.5 & 0 & 075 \\
\hline $\begin{array}{l}\text { g) Está redigido na formatação indicada pela ABNT (Associaçảo Brasileira de } \\
\text { Normas Técricas)? }\end{array}$ & 0.5 & 0 & 025 \\
\hline
\end{tabular}

Fonte: Curitiba (2009b).

\section{Terceiro movimento:}

O terceiro movimento flagrado neste estudo, e que trata da incorporação das matrizes da Prova e da Provinha Brasil como o currículo de fato para a rede municipal de Curitiba. Tal processo foi detectado em outro mecanismo de formação permanente dos professores e professoras da rede municipal, denominado de "Semana de Estudos Pedagógicos" (SEP).

A Semana de Estudos Pedagógicos constitui um "momento de estudo em que os profissionais da educação refletem 
coletivamente sobre temas de caráter pedagógico e aspectos teórico-metodológicos das temáticas que envolvem o cotidiano da escola e da sala de aula" (Departamento de Ensino Fundamental, 2009, p. 1).

Portanto, em se tratando do cotidiano da especificidade da escola e da sala de aula, supõe-se que haja autonomia para a definição da temática a ser trabalhada, visto que os problemas de ensino-aprendizagem de cada escola são distintos, mas o item (d) das orientações limita tal autonomia. Consta nesse item:

O tema central e as temáticas das palestras devem prever o trabalho com as áreas do conhecimento, considerados os resultados da Prova Brasil, Avaliação do Ciclo I, Ciclo II e EJA, Provinha Brasil ( $2^{\circ}$. Ano), bem como as propostas pedagógicas das unidades escolares para, nessa perspectiva, estabelecer as ações para o aprimoramento da prática pedagógica dos profissionais da escola, tendo em vista a melhoria da qualidade do ensino e de seus resultados. (Departamento de Ensino Fundamental, 2009a, p. 1. Grifo nosso).

Mesmo sabendo-se da necessidade de um determinado grau de direcionamento na formação continuada dos professores, há que se valorizar a percepção das escolas no que se refere ao mapeamento de seus problemas, bem como de suas necessidades de debate e diálogo sobre determinados assuntos, próprios dos problemas enfrentados pelo coletivo de cada escola. Nesse sentido, o projeto de Semana de Estudos Pedagógicos acerta ao permitir que as escolas discutam e sistematizem suas demandas de formação continuada, porém, novamente flagra-se o movimento de supervalorização das Matrizes da Prova e da Provinha Brasil, em detrimento das necessidades sistematizadas nos projetos das escolas.

Em documento disponibilizado pela Escola Municipal Professor Francisco Hübert, contendo seu projeto para a SME com duas palestras, pois essa escola tem sob sua 
responsabilidade a organização de apenas dois dias dos cinco que compõem a SEP. Os temas dessas palestras eram: "Como entender e desenvolver o processo de letramento em alunos com distúrbios de aprendizagem?" e "Como trabalhar com os distúrbios de aprendizagem e reverter esse quadro para o sucesso?". A princípio, tais temas estariam amparados nas orientações, visto que trata de problema levantado no interior da escola, como fruto de debates do seu coletivo, além de encontrarem-se vinculados a "caráter pedagógico e aspectos teórico-metodológicos das temáticas que envolvem o cotidiano da escola e da sala de aula", como expressa o item (a) do Ofício $n^{\circ} 013 / 2009$, já mencionado, além do fato de ambos os temas cumprirem o objetivo de instrumentalizar as professoras para um trabalho frente à diversidade dos alunos em sala de aula, consolidada com as políticas de inclusão.

Ocorre, porém, que a gerente pedagógica do Departamento de Ensino Fundamental (Cristina Rolim), expressou-se contrária aos temas das palestras constantes do projeto da escola, com base na seguinte argumentação:

Após análise do projeto, consideramos que:

O projeto apresenta/tem justificativa, objetivos, dinâmica de desenvolvimento, recursos e resultados esperados.

Os temas propostos pela escola não estão de acordo com o Ofício n. 013/2009 recomenda que o 'tema central e as temáticas das palestras devem prever o trabalho com as áreas do conhecimento, considerando os resultados da Prova Brasil, Avaliações do Ciclo I, Ciclo II e EJA, Provinha Brasil ( $2^{\circ}$ ano), bem como as propostas pedagógicas das unidades escolares para, nessa perspectiva, estabelecer as ações para o aprimoramento da prática pedagógica dos profissionais da escola, tendo em vista a melhoria da qualidade do ensino e de seus 
resultados' (item d);

Há necessidade de rever a proposta, seguindo as orientações do Ofício anteriormente recomendado. (Departamento de Ensino Fundamental, 2009b -. Grifos da autora).

Considerando esse parecer da gerente pedagógica, a escola reformulou o seu projeto, inclusive alterando as palestras, que passaram a ser sobre o mesmo tema, mas com outra abordagem, apresentando os seguintes títulos: "Letramento: um mundo repleto de oportunidades para acertar" e "Letramento: avaliando, compreendendo e modificando posturas de ensinar e aprender". Mesmo assim, o parecer foi:

Após análise do projeto, consideramos que:

O projeto apresenta/tem justificativa, objetivos, dinâmica de desenvolvimento, recursos e resultados esperados.

Os temas propostos pela escola não estão de acordo com o Ofício n. 013/2009 recomenda que o 'tema central e as temáticas das palestras devem prever o trabalho com as áreas do conhecimento, considerando os resultados da Prova Brasil, Avaliações do Ciclo I, Ciclo II e EJA, Provinha Brasil ( $2^{\circ}$ ano), bem como as propostas pedagógicas das unidades escolares para, nessa perspectiva, estabelecer as ações para o aprimoramento da prática pedagógica dos profissionais da escola, tendo em vista a melhoria da qualidade do ensino e de seus resultados' (item d);

Os objetivos não estão articulados com as orientações do Ofício Circular n. 013/2009 e com as orientações dadas no parecer anterior. 
Há necessidade de rever a proposta, seguindo as orientações do Ofício anteriormente recomendado. (Departamento de Ensino Fundamental, 2009c - Grifos da autora).

Portanto, os dois pareceres, datados de 17 de abril de 2009 e de 12 de maio de 2009, bem como o Ofício 013/2009, corroboram o flagrante do movimento da política educacional do município de Curitiba de considerar como o currículo a ser trabalhado pelos professores e professoras da rede municipal as Matrizes da Prova e da Provinha Brasil, alinhando a política educacional do município, de forma vertical, à política educacional do governo federal, o que se constitui de outro flagrante do movimento da política educacional do município de Curitiba com vistas à melhoria do IDEB do município para os anos iniciais do Ensino Fundamental, e que acabam por confirmar o poder indutor de políticas educacionais próprio do IDEB.

\section{Considerações Finais}

Em outra passagem, é possível flagrar essa redefinição de forma mais clara. A representante da SME esclarece que, "além da parte administrativa dos núcleos nós temos pedagogas de núcleo, temos alfabetizadoras de núcleo, estamos colocando professores da área de Matemática”, porém, ressalta que "essas equipes então [...] vinculadas a este departamento tecnicamente, não administrativamente", o que significa dizer que esse pessoal deve seguir as orientações do núcleo central da política educacional. Nesse caso, esse núcleo central, a SME, definiu a prioridade do trabalho desses profissionais, os quais, devido ao próprio processo de (re)definição curricular, passou a ter que responder para as escolas sobre os melhores encaminhamentos para o desenvolvimento do trabalho pedagógico com as matrizes de referência da Prova e da Provinha Brasil, a ponto de, no ano de 2009, os núcleos regionais terem realizado três reuniões no mês da aplicação das avaliações da Prova Brasil. Como 
afirma a diretora Juliane Sonda, da escola Professor Francisco Hübert, "as convocações eram sempre para a diretora, a vice e as pedagogas", acrescentando ainda que "todo o setor pedagógico e administrativo tinha que se ausentar da escola para essas reuniões, isso eu nunca tinha visto em 8 anos de direção". Relato semelhante foi feito pela diretora Luciana Alves, da Escola Madre Antônia. Cabe salientar que as duas escolas pertencem a núcleos diferentes, confirmando que há uma determinação central para o desempenho dos núcleos, a qual objetiva a melhoria do desempenho das escolas nas avaliações da Prova Brasil, impactando, com isso, na melhoria do IDEB do município.

Outro movimento da política educacional que foi flagrado por esta pesquisa trata da relação entre o binômio "autonomia x controle", em que foi possível perceber uma retomada por parte do órgão central de gestão da política educacional do controle do trabalho pedagógico desenvolvido no interior das escolas. Tal controle ficou claro quando a representante da SME expressou que os mecanismos de avaliação próprios da SME têm produzido uma gama de informações que, após serem sistematizadas e analisadas, retornam em forma de caderno, contendo resultados gerais da rede, do núcleo a que a escola pertence e da própria escola, além do resultado e análise "questão por questão e orientação pedagógica, orientação para se trabalhar" (Salamunes apud Zampiri, 2009, p. 178).

Esse processo expressa o grau de controle de que hoje a SME faz uso, a ponto de saber quem são os alunos (nome e sobrenome) que já sabem ler e escrever seu nome completo, os que dominam os números, ou mesmo que já reconhecem as letras do alfabeto, no entanto, tal controle tem mostrado na prática encaminhamentos frágeis. Por que o grau de mapeamento dos problemas encontra-se tão avançado, as respostas exigem, do outro lado, um compromisso do gestor municipal em comprometer-se na resolução dos problemas. Para tanto, são necessárias políticas distintas, tanto na alocação de pessoal qualificado para enfrentar tais problemas quanto também 
na consolidação de mecanismos distintos de investimento financeiro para as escolas ditas "prioritárias", caso contrário, se estará apenas dificultando mais ainda o árduo trabalho de melhorar a qualidade das escolas. Como afirma Santos Guerra:

Se a mudança só for efetuada a partir das prescrições provenientes da hierarquia, e não em virtude da compreensão e das exigências dos profissionais que as praticam, haverá dificuldades graves para conseguir uma melhora profunda. (Santos Guerra, 2007, p. 23)

Os professores e professoras precisam perceber uma disposição efetiva por parte dos responsáveis pela política educacional em assumir sua parte na responsabilidade, de um lado, para com a realidade expressa pelas avaliações, e de outro, no processo de resolução dos problemas, caso contrário, tais avaliações e o controle estarão limitando-se apenas a individualizar a culpa no professor e ou escola, o que somente reforçará uma compreensão por parte dos/as profissionais que se encontram no interior das escolas de que tais avaliações servem apenas para a conformação (corpos e mentes) e a submissão, ficando à mercê da arbitrariedade das instâncias hierárquicas superiores.

Sobre a disposição de assumir responsabilidades por parte de todos, Santos Guerra afirma ainda que:

Falo da disposição positiva de todos os envolvidos na avaliação. Isso diz respeito também à Administração. Se a avaliação revela carências, deficiências ou erros na gestão do sistema educacional, os professores precisam perceber que existe disponibilidade para assumir as decisões de melhora. Se não for assim, o professorado verá a avaliação como um fenômeno de hierarquização e de controle. (Santos Guerra, 2007, p. 57)

Por fim, conclui o autor, "com frequência se exige que as 
avaliações gerem uma mudança automática, sem que se ponham em funcionamento os meios materiais para que tal mudança seja possível" (Santos Guerra, 2007, p. 86).

Nesse sentido, a atual gestão ainda não ultrapassou esse limite de se comprometer com parte da solução dos problemas detectados pelas avaliações, implementando políticas que viessem garantir ao grupo de escolas que se encontram com os desempenhos mais baixos, principalmente quando esse desempenho apresenta vinculação com o nível socioeconômico, que haja uma política efetiva de melhoria diferenciada dessas escolas, para que tais condições privilegiadas consigam compensar parte da estrutura desfavorável dos alunos e alunas dessas escolas.

O último flagrante proveniente do movimento da política educacional domunicípio diz respeito a uma nova característica da sua política educacional, a qual sempre se pautou, vangloriandose sempre disso, por políticas próprias. Na expressão de Ferreira (2008, p. 227), Curitiba sempre foi tratada como o "umbigo da terra", ou, dito de outra forma, em questão de política, Curitiba sempre soube achar soluções criativas para seus problemas, o que não encontrou respaldo nas análises frente às políticas educacionais implementadas pela gestão municipal desde 2004, tendo-se verificado um alinhamento da política educacional do município com a política educacional do governo federal. Isso significa dizer que o poder de indução das políticas gestadas pelo Governo Federal gerou impacto inclusive nas características próprias da política municipal de Curitiba, a qual sempre foi motivo de orgulho de seus gestores. Dessa forma, hoje a política educacional do município não cria, mas sim busca reproduzir, da forma mais fiel possível, a política do governo federal, o que, em parte, é motivado pelo próprio modelo apresentado pela representante da SME, pois, para que um modelo de reforma sustentada na racionalidade técnica obtenha êxito, os gestores que ocupam cargos superiores na hierarquia precisam também apresentar competência, a qual, como foi visto, é expressa em executar aquilo que outros pensaram. Nesse caso, o papel de 
bom executor recai sobre a Secretaria Municipal de Educação, e os criadores constituem uma hierarquia superior, organizada no Ministério da Educação, no governo central.

Por fim, cabe destacar que esta pesquisa, além de ter evidenciado movimentos da política com potencial de gerar impacto na melhoria do IDEB do município, ainda detectou um movimento da política gerado pelo poder de indução, característica própria dos mecanismos avaliativos e da criação de um índice de monitoramento de qualidade, sendo possível perceber uma mudança na tendência do movimento do Indicador de Rendimento da rede municipal a partir da criação do IDEB, evidenciando o potencial indutor das avaliações e do índice.

Dadas essas considerações finais, compreendo que, mesmo com as limitações deste professor que ousou trilhar o rico caminho da pesquisa, o trabalho sistematizado aqui constitui, mesmo que de forma limitada e tosca, uma pequena contribuição para o olhar da política educacional do município de Curitiba para os anos iniciais do Ensino Fundamental, sem a pretensão de que tal pesquisa encerre esse tema. Longe disso. Inclusive, penso ter sido esse um passo pequeno na imensidão do mundo da política educacional.

\section{Notas}

*Professor da Rede Municipal de Ensino de Curitiba. Mestre e Doutorando em Educação pela UFPR. douglasdanilodittrich@gmail.com

${ }^{1}$ Utilizo aqui a expressão "escolas eficazes", mas pessoalmente prefiro o conceito "escolas efetivas" para expressar o que os autores afirmam significar uma 'escola eficaz'.

${ }^{2}$ Escola \& Universidade é um projeto de qualificação profissional continuada que coloca os professores da rede municipal em contato com professores das Instituições de Ensino Superior, buscando trazer para dentro das escolas municipais as contribuições técnicas e científicas para a melhoria e aprimoramento do trabalho pedagógico das escolas. 


\section{Referências Bibliográficas}

BOURDIEU, Pierre. O poder simbólico. Tradução: Fernando Tomaz (português de Portugal). 11. ed. Rio de Janeiro: Bertrand Brasil, 2007.

CURITIBA. Manual do projeto Universidade \& Escola. Secretaria Municipal de Educação de Curitiba. Curitiba: 2009a.

. Tabela de pontos para os critérios de avaliação de projetos

Escola \& Universidade. Secretaria Municipal de Educação de Curitiba. Curitiba, 2009b.

. Caderno Pedagógico: alfabetização. Secretaria Municipal de Educação de Curitiba. Curitiba: 2008a.

. Caderno Pedagógico: Língua Portuguesa. Secretaria Municipal de Educação de Curitiba. Curitiba: 2008 b.

. Caderno Pedagógico: Matemática. Secretaria Municipal de Educação de Curitiba. Curitiba: 2008c.

. Resultados da Avaliação do Ciclo I da Rede Municipal de Ensino de Curitiba - 2007. Secretaria Municipal de Educação de Curitiba. Curitiba: 2007.

. Diretrizes Curriculares para a Educação Municipal de Curitiba. v. 3. ENSINO FUNDAMENTAL. Secretaria Municipal de Educação de Curitiba. Curitiba: 2006.

CURY, Carlo Roberto J. Políticas inclusivas e compensatórias na Educação Básica. Cadernos de Pesquisa, v. 35, n. 124, p. 11-32. jan/ abr. 2005 .

. Direito à educação: direito à igualdade, direito à diferença. Cadernos de Pesquisa, n. 116, p. 245-262. julho/2002. 
DARLING-HAMMOND, Linda; ASCHER, Carol. Construindo sistemas de controle em escolas urbanas. Estudos em Avaliação Educacional, v. 17, n. 35, p. 07-48. set/dez. 2006.

DEPARTAMENTO DE ENSINO FUNDAMENTAL. Ofício Circular n. 013/2009. Assunto: Orientações para SEP - 2009. Curitiba: SME, 2009a.

. Parecer Projeto da Semana de Estudos Pedagógicos Escola Municipal Professor Francisco Hübert. Curitiba: SME, 12/05/2009b.

. Parecer Projeto da Semana de Estudos Pedagógicos Escola Municipal Professor Francisco Hübert. Curitiba: SME, 17/04/2009c.

FERNANDES, Reinaldo. Índice de Desenvolvimento da Educação Básica - IDEB. Brasília: INEP, 2007. Disponível em: <http://www. publicacoes.inep.gov.br/detalhes.asp?pub=4121>. Acesso em: 22 ago. 2009.

FERREIRA, Valéria Milena Röhrich. Tecendo uma cidade modelar: relações entre currículo, educação e projeto da cidade de Curitiba na década de 1990. 2008. 261 f. Tese (Doutorado em Educação) - Pontífice Universidade Católica de São Paulo, São Paulo, 2008.

FRANCO, Creso. A pesquisa em eficácia escolar no Brasil: evidências sobre o efeito das escolas e fatores associados à eficácia escolar. In: BROOKE, Nigel; SOARES, José Francisco (Org.). Pesquisa em eficácia escolar: origem e trajetórias. Belo Horizonte: Editora UFMG, 2008, p. 482-500.

GIMENO SACRISTÁN, José. O currículo: uma reflexão sobre a prática. 3. ed. Porto Alegre: Artmed, 2000.

. FERNANDES, Reinaldo. Índice de Desenvolvimento da Educação Básica (IDEB): metas intermediárias para a sua trajetória no Brasil, Estados, Municípios e escolas. Disponível em: $<$ http://www. 
inep.gov.br/salas/download/ideb/ideb_projecoes.pdf>. Acesso em: 22 ago. 2009.

. Nota Técnica - Índice de Desenvolvimento da Educação Básica (IDEB). Brasília : INEP, Disponível em: <http://portalideb. inep.gov.br/index.php?option=com_content\&task=view\&id=4\&item $\mathrm{id}=5>$. Acesso em: 22 ago. 2009.

. Matriz de Referência de Língua Portuguesa - Saeb/Prova Brasil - Tópicos e Descritores - $4^{\mathrm{a}}$ série do Ensino Fundamental. Disponível em: $<$ http://www.inep.gov.br/salas/download/prova_brasil/ exemplos_questoes/lp/p04_site.pdf $>$. Acesso em: 21 nov. $200 \overline{9}$.

MURILLO TORRECILLA, Francisco Javier. La investigación sobre eficacia escolar. Barcelona: Octaedro, 2005a.

. Um panorama da pesquisa ibero-americana sobre a eficácia escolar. In: BROOKE, Nigel; SOARES, José Francisco (Org.). Pesquisa em eficácia escolar: origem e trajetórias. Belo Horizonte: Editora UFMG, 2008b, p. 466-481.

Apresentação. Revista Eletrônica Iberoamericana sobre Calidad Eficacia y Cambio in Educación, v. 5, n. 3, 2007.

MURILLO TORRECILLA, Francisco Javier; CUENCA, Ricardo. Construyendo consensos en torno al concepto de calidad. Revista Iberoamericana sobre calidad, eficacia y cambio en educación (REICE), v. 5, n. 3, editorial, 2007.

MURILO TORRECILLA, Francisco Javier et al. Investigación Iberoamericana sobre eficácia escolar. Bogotá: Convênio Andrés Bello, 2007.

SAMMONS, Pam. As características-chave das escolas eficazes. In: BROOKE, Nigel; SOARES, José Francisco (Org.). Pesquisa em eficácia escolar: origem e trajetórias. Belo Horizonte: Editora UFMG, 2008, p. 335-392. 
SANTOS GUERRA, Miguel Ángel. Uma Flecha no Alvo: a avaliação como aprendizagem. São Paulo: Loyola, 2007.

ZAMPIRI, Marilene. Políticas educacionais e resultados estudantis: a medida da política em ação. 2009. 183 f. Dissertação (Mestrado em Educação) - Setor de Educação da Universidade Federal do Paraná, Curitiba, 2009. 